\title{
Dilemmas, Confusion, and Misconceptions ( Related to Small Airways Directed Therapy
}

\author{
Federico Lavorini, MD, PhD; Søren Pedersen, MD, PhD; and Omar S. Usmani, MBBS, PhD; on behalf of the Aerosol Drug \\ Management Improvement Team (ADMIT)
}

\begin{abstract}
During the past decade, there has been increasing evidence that the small airways (ie, airways $<2 \mathrm{~mm}$ in internal diameter) contribute substantially to the pathophysiologic and clinical expression of asthma and COPD. The increased interest in small airways is, at least in part, a result of innovation in small-particle aerosol formulations that better target the distal lung and also advanced physiologic methods of assessing small airway responses. Increasing the precision of drug deposition may improve targeting of specific diseases or receptor locations, decrease airway drug exposure and adverse effects, and thereby increase the efficiency and effectiveness of inhaled drug delivery. The availability of small-particle aerosols of corticosteroids, bronchodilators, or their combination enables a higher total lung deposition and better peripheral lung penetration and provides added clinical benefit, compared with largeparticle aerosol treatment. However, a number of questions remain unanswered about the pragmatic approach relevant for clinicians to consider the role of small airways directed therapy in the day-to-day management of asthma and COPD. We thus have tried to clarify the dilemmas, confusion, and misconceptions related to small airways directed therapy. To this end, we have reviewed all studies on small-particle aerosol therapy systematically to address the dilemmas, confusion, and misconceptions related to small airways directed therapy.
\end{abstract}

CHEST 2017; 151(6):1345-1355

KEY WORDS: aerosols; asthma; COPD; inhalers; small airways; small particles

Inhaled therapy is the mainstay of the modern treatment of asthma and COPD. However, little consideration has been given to the potential advantage of targeting specific airway regions within the lungs. In theory, by increasing the precision of drug deposition, it may be possible to target specific disease or receptor locations and decrease drug exposure and side effects, thus increasing the efficiency and effectiveness of inhaled drug delivery in daily clinical practice. ${ }^{1}$

The small airways (airways with internal diameter $<2 \mathrm{~mm}$ ) comprise airway
ABBREVIATIONS: BDP = beclomethasone dipropionate; $\mathrm{CFC}=$ chlorofluorocarbon; DPI = dry powder inhaler; $\mathrm{GSD}=$ geometric standard deviation; HFA = hydrofluoroalkane; ICS = inhaled corticosteroid; LABA $=$ long-acting $\beta 2$-adrenergic bronchodilator; $\mathrm{MMAD}=$ mass median aerodynamic diameter; $\mathrm{pMDI}=$ pressurized metered-dose inhaler; $\mathrm{VHC}=$ valved holding chamber

AfFiliations: From the Department of Experimental and Clinical Medicine (Dr Lavorini), Careggi University Hospital, Florence, Italy; the Pediatric Research Unit (Dr Pedersen), University of Southern Denmark, Kolding Hospital, Kolding, Denmark; and the Airways Disease Section (Dr Usmani), National Heart and Lung Institute, Imperial College London and Royal Brompton Hospital, London, England.
FUNDING/SUPPORT: O. S. U. is the recipient of a National Institute for Health Research Career Development fellowship. The study was supported by the National Institute for Health Research Respiratory Disease Biomedical Research Unit at the Royal Brompton and Harefield National Health Service Foundation Trust and Imperial College London, London, England.

CORRESPONDENCE TO: Federico Lavorini, MD, PhD, Department of Experimental and Clinical Medicine, Careggi University Hospital, Largo Brambilla 3, 50134, Florence, Italy; e-mail: federico.lavorini@ unifi.it

Copyright (C) 2016 American College of Chest Physicians. Published by Elsevier Inc. All rights reserved.

DOI: http://dx.doi.org/10.1016/j.chest.2016.07.035 
generations eight to $23^{2}$ and are a significant component of obstructive airway disease. Emphysema classically involves the terminal bronchioles, ${ }^{3}$ but it is increasingly recognized that asthma also involves small airways, ${ }^{4,5}$ not only in patients with severe asthma ${ }^{6}$ but also in those with milder disease. ${ }^{7}$ Distal airway inflammation and dysfunction also have been demonstrated in distinct clinical asthma phenotypes, ${ }^{8}$ such as nocturnal asthma, ${ }^{9,10}$ exercise-induced asthma, ${ }^{11}$ and allergic asthma. ${ }^{12}$ These phenotypes support the targeting of inhaled drug therapy toward the small airways.

Most inhaled therapies do not reach the small airways sufficiently. ${ }^{13-18}$ Although the drug particle size pattern may vary markedly among inhalers, conventional pressurized metered-dose inhalers (pMDIs) and most dry powder inhalers (DPIs) emit drug particles too large to target the small airways effectively (Table 1 ). Overall, these aerosol devices deposit approximately $20 \%$ of the drug dose in the lungs, ${ }^{19}$ with a high proportion of the drug being deposited in the oropharynx, which can cause local and systemic effects through gastrointestinal absorption..$^{20}$ However, technological advances in device engineering and drug formulation have led to a new generation of inhalers emitting small-particle drug aerosol at slower velocities, with enhanced lung deposition $(\sim 50 \%)$ and, most importantly, more effective aerosol penetration into the lung periphery. ${ }^{13-18}$ These new inhalers and drug formulations include solution-based hydrofluoroalkane (HFA)-propelled pMDIs delivering aerosols of inhaled corticosteroid (ICS)—namely, beclomethasone dipropionate (BDP), ciclesonide, and flunisolide; long-acting $\beta 2$-adrenergic bronchodilators (LABAs)-namely, formoterol; and ICS/LABA fixed-dose combinations-namely, BDP/ formoterol. Furthermore, a multidose DPI (NEXThaler, Chiesi, Italy) delivering a small-particle ICS/LABA drug combination, ${ }^{21}$ as well as a novel device categorynamely, a soft mist inhaler (Boehringer Ingelheim), delivering small-particle aerosols of long-acting bronchodilators-also have been developed. ${ }^{22}$

Because of the high drug deposition in the lungs and better targeting of the small airways, these new inhaler devices in theory should be more effective for treating the peripheral lung compartment in patients with asthma and COPD. Studies in patients with asthma ${ }^{7,13,14,23-25}$ and $\mathrm{COPD}^{26}$ show larger improvements in markers of small airway function with small-particle aerosols, compared with large-particle aerosols, and lend support to this theory. However, several questions still need clarification. For instance, the
TABLE 1 ] Drug Particle Size and Inhaler Type of Most Frequently Prescribed ICS, LABA, LAMA, and ICS/LABA Formulations

\begin{tabular}{|c|c|c|}
\hline ICS & Inhaler Type & $\mathrm{MMAD}^{a}{ }^{a} \mu \mathrm{m}$ \\
\hline $\begin{array}{l}\text { Fluticasone } \\
\text { propionate }\end{array}$ & Diskus DPI & 5.4 \\
\hline Fluticasone furoate & Ellipta DPI & $3.0-3.9$ \\
\hline $\begin{array}{l}\text { Fluticasone } \\
\text { propionate }\end{array}$ & $\begin{array}{l}\text { Suspension HFA } \\
\text { pMDI }\end{array}$ & 2.4 \\
\hline Budesonide & Turbuhaler DPI & 4.0 \\
\hline BDP & $\begin{array}{l}\text { Suspension HFA } \\
\text { pMDI }\end{array}$ & 4.1 \\
\hline BDP & Solution HFA pMDI & 1.1 \\
\hline Ciclesonide & Solution HFA pMDI & 1.1 \\
\hline Flunisolide & Solution HFA pMDI & 1.2 \\
\hline \multicolumn{3}{|c|}{ LABA } \\
\hline Formoterol & Solution HFA pMDI & 1.2 \\
\hline Salmeterol & $\begin{array}{l}\text { Suspension HFA } \\
\text { pMDI }\end{array}$ & 2.8 \\
\hline Indacaterol & Breezhaler DPI & 3.2 \\
\hline Vilanterol & Ellipta DPI & $1.8-2.5$ \\
\hline \multicolumn{3}{|c|}{ LAMA } \\
\hline \multirow[t]{2}{*}{ Tiotropium } & Soft mist inhaler & 2.0 \\
\hline & HandiHaler DPI & 3.9 \\
\hline Aclidinium & Genuair DPI & 2.4 \\
\hline Glycopyrronium & $\begin{array}{l}\text { Breezhaler } \\
\text { DPI }\end{array}$ & 2.8 \\
\hline \multicolumn{3}{|c|}{ ICS/LABA } \\
\hline Formoterol/BDP & $\begin{array}{l}\text { Solution HFA } \\
\text { pMDI }\end{array}$ & 1.5 \\
\hline Formoterol/BDP & NEXThaler DPI & 1.5 \\
\hline $\begin{array}{c}\text { Salmeterol/ } \\
\text { fluticasone } \\
\text { propionate }\end{array}$ & $\begin{array}{l}\text { Suspension HFA } \\
\text { pMDI }\end{array}$ & 2.7 \\
\hline $\begin{array}{c}\text { Salmeterol/ } \\
\text { fluticasone } \\
\text { propionate }\end{array}$ & Diskus DPI & 3.5 \\
\hline $\begin{array}{l}\text { Formoterol/ } \\
\text { budesonide }\end{array}$ & Turbuhaler DPI & 3.0 \\
\hline $\begin{array}{c}\text { Formoterol/ } \\
\text { fluticasone } \\
\text { propionate }\end{array}$ & $\begin{array}{l}\text { Suspension HFA } \\
\text { pMDI }\end{array}$ & $3.15-3.52$ \\
\hline
\end{tabular}

$\mathrm{BDP}=$ beclomethasone dipropionate; DPI = dry powder inhaler; HFA = hydrofluoroalkane; ICS = inhaled corticosteroid; $\mathrm{LABA}=$ long-acting $\beta 2$-adrenergic agonist; LAMA = long-acting muscarinic antagonist; MMAD = mass median aerodynamic diameter; pMDI = pressurized metered-dose inhaler.

${ }^{a}$ Drug particle size is expressed as MMAD. (MMAD data are adapted from Usmani, ${ }_{14,15}$ Chapman et al, ${ }_{1}^{16}$ Colthorpe et al, ${ }_{1}^{17}$ Lock et al, ${ }_{1}^{18}$ and Labiris et al. ${ }^{20}$ )

optimal particle size for an inhaled drug to reach and deposit into the small airways effectively has not been defined clearly, as reflected by the different terms and 
sizes (ie, submicron, ${ }^{27}<1 \mu \mathrm{m}$; ultrafine, ${ }^{28} 1.1 \mu \mathrm{m}$; extrafine, ${ }^{21} 1.5 \mu \mathrm{m}^{2}$ ) used to describe the finer smallparticle aerosols delivered by these inhalers. In agreement with the literature, ${ }^{13-15}$ we define "small particles" as those with a size expressed as mass median aerodynamic diameter (MMAD) - the aerodynamic diameter above and below which $50 \%$ of the mass resides $^{20}$-of $<2 \mu \mathrm{m}$. We also call particles $<1 \mu \mathrm{m}$ "submicron" and those $>2 \mu \mathrm{m}$ "large" or "coarse," as has been used by other authors. 27,29

The aim of this article is to address six clinical questions related to the use of small-particle aerosols that are relevant to practicing health-care professionals in their day-to-day clinical practice. These questions were selected by means of consensus by the members of the Aerosol Drug Management Improvement Team (www.admit-inhalers.org), a working group of physicians with combined clinical and research expertise on the topic of inhaled therapy for respiratory diseases. The six questions listed are not meant to be hierarchical or all-inclusive, but, in our view, they cover the major concerns practicing clinicians have related to smallparticle aerosol therapy. To address the questions, we scanned electronic databases (PubMed, MEDLINE, Embase, Scopus, and Google Scholar) from the date of inception up to December 2015 with cross-search using the following keywords: "aerosols," "inhalation," "small particles," "fine particles," "extrafine particles," "chronic obstructive pulmonary disease," "COPD," "asthma," and "inhaler." All studies considered to be relevant for the six questions were evaluated; no restriction was placed on study design and language of publication.

\section{Questions}

\section{Is Particle Size Important to Achieve Better Lung Deposition?}

The terms and definitions used to describe the principles of aerosol medicine and particle size are important to mention to be able to address the question. Aerosol particles range in size between 0.01 and $100 \mu \mathrm{m} .{ }^{30}$ Because the aerodynamic behavior of an aerosolized particle is influenced critically by its mass, it is important to describe the size distribution of the aerosolized particles. In clinical studies, the MMAD and the geometric standard deviation (GSD) often are used to characterize the dimensions of an aerosol. The MMAD divides the aerosol size distribution in one-half; it represents the diameter at which $50 \%$ of the particles of an aerosol by mass are larger and $50 \%$ are smaller. ${ }^{30}$ In general, particles with a MMAD $>5 \mu \mathrm{m}$ are most likely to deposit by impaction in the oropharynx and be swallowed. Conversely, particles with a MMAD $<5 \mu \mathrm{m}$, the so-called respirable particles, are those with the highest probability of penetrating beyond the oropharynx and depositing in the lungs. ${ }^{30}$ The proportion of particles within the aerosol that are $<5 \mu \mathrm{m}$ is often referred to as the "fine particle fraction" or the "fine particle dose," if expressed in absolute mass of drug. ${ }^{28}$ Both the particle size and fine particle fraction of an aerosol play a significant role in the deposition of an inhaled drug and its relative distribution within the large and small airways. ${ }^{31-33}$ The GSD measures the dispersion of the particle diameter and is defined as the ratio of the median diameter to the diameter at \pm 1 SD from the median diameter. ${ }^{30}$ If the particle size varies over a wide range (ie, GSD > 1.2), the aerosol is described as having a polydisperse particle distribution; if the particles are of similar size (ie, GSD < 1.2) the aerosol particle distribution is described as monodisperse. ${ }^{30}$

The study of monodisperse aerosols has increased our knowledge of the effects of particle size on regional drug deposition in the human lung. ${ }^{34}$ Usmani et a ${ }^{35,36}$ undertook gamma scintigraphy to investigate the radioaerosol lung distribution of monodisperse salbutamol particles with MMADs of 1.5-, 3.0-, and 6.0- $\mu \mathrm{m}$ sizes in patients with mild asthma (Fig 1). The authors showed $1.5-\mu \mathrm{m}$ particles achieved higher total lung deposition (56\% of the emitted dose) than did $3.0-$ and $6.0-\mu \mathrm{m}$ particles (51\% and $46 \%$ of the emitted dose, respectively) (Table 2). ${ }^{36}$ They also observed significantly greater penetration into the peripheral airways with the smaller particles. Additionally, although slow inhalation $(30 \mathrm{~L} / \mathrm{min})$ was better than fast inhalation $(>60 \mathrm{~L} / \mathrm{min})$ for effective lung deposition with 3.0- and $6.0-\mu \mathrm{m}$ particles, lung deposition was less affected by the differences in inhalation flow with $1.5-\mu \mathrm{m}$ particles. ${ }^{36}$ Despite the higher deposition with $1.5-\mu \mathrm{m}$ particles, large-particle (3.0 and $6.0 \mu \mathrm{m}$ ) salbutamol aerosols improved $\mathrm{FEV}_{1}$ more effectively than did $1.5-\mu \mathrm{m}$ aerosols. ${ }^{36}$ Zanen et $\mathrm{al}^{37}$ also observed that inhalation of monodisperse salbutamol aerosols with a MMAD of $2.8 \mu \mathrm{m}$ caused more marked $\mathrm{FEV}_{1}$ increases than that obtained with monodisperse salbutamol aerosols with a MMAD of $1.5 \mu \mathrm{m}$.

Although these studies ${ }^{36,37}$ have improved our insights into the effects of particle size on lung deposition and airway function, they have assessed the effects of treatment by using $\mathrm{FEV}_{1}$, which mainly reflects largeairway patency. It would have been interesting to know the results if the main outcome had been effects on smallairway physiologic parameters, such as peripheral airway 

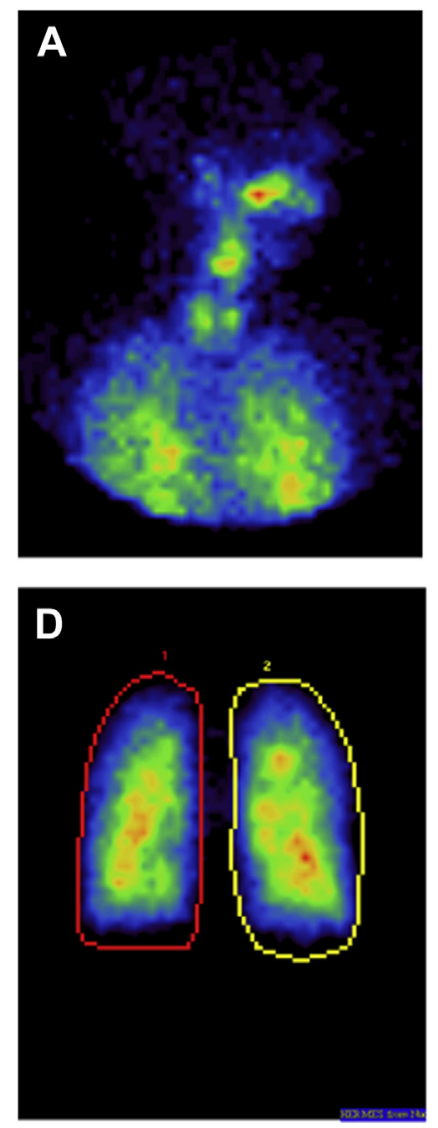

$1.5 \mu \mathrm{m}$
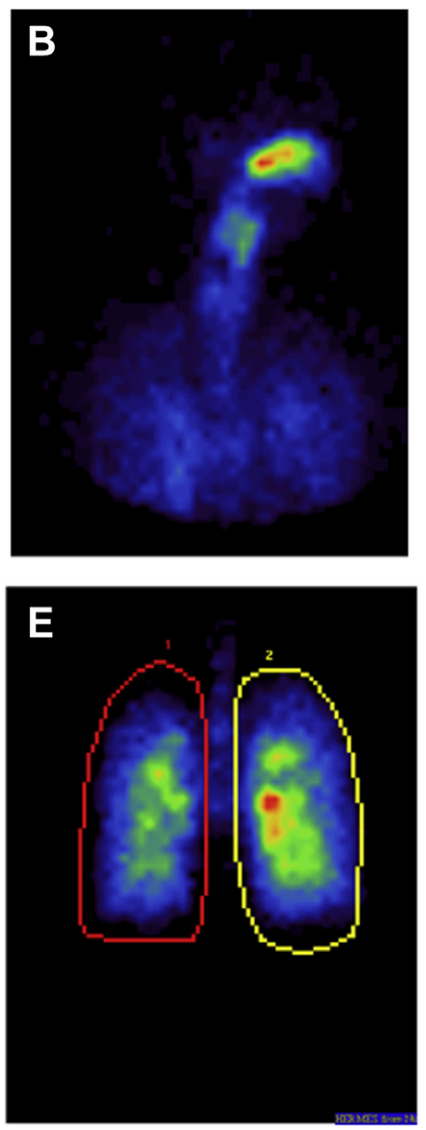

$3 \mu \mathrm{m}$
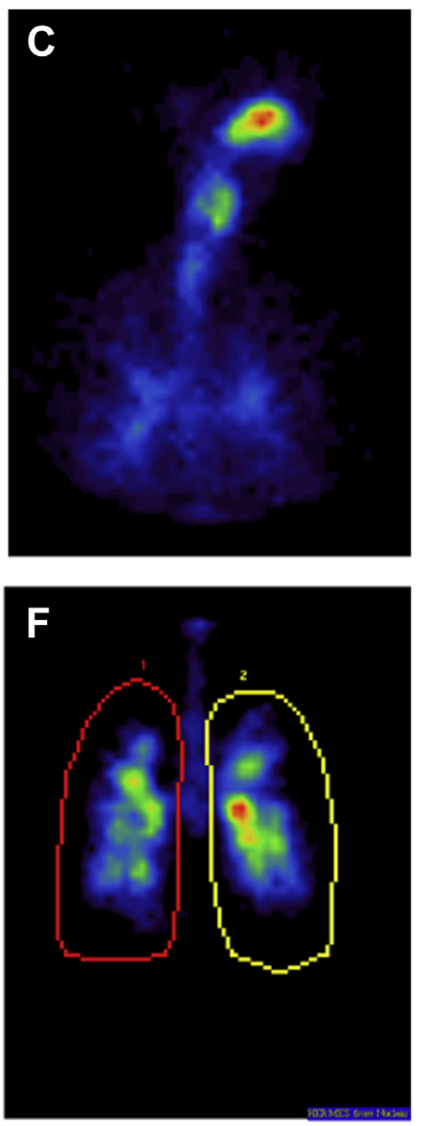

$6 \mu \mathrm{m}$

Figure $1-A-C$, Oropharyngeal and posterior thorax (D-F) gamma camera images of aerosol deposition obtained by using technetium-99m-labeled salbutamol particles of 1.5-, 3-, and 6- $\mu \mathrm{m}$ mass median aerodynamic diameter. Red areas indicate regions of highest radioactivity, and black areas

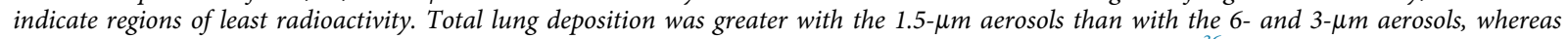
oropharyngeal deposition increased with increasing particle size. (Adapted with permission from Usmani et al ${ }^{36}$.)

resistance measured with forced oscillometry, ${ }^{38}$ air trapping measured with body plethysmography, ${ }^{38}$ or ventilation heterogeneity measured with the singleor multiple-breath nitrogen washout test. ${ }^{39,40}$ In addition, both studies, ${ }^{36,37}$ investigated the effects of monodisperse $($ GSD $<1.2)$ salbutamol, whereas commercially available aerosols are polydisperse (GSD > 1.2), consisting of a mix of different sizes of particles. In this case, not only is MMAD important but so is the particle size distribution in the overall clinical effectiveness of the aerosol. Patients should benefit the most if both the large and the small airways are treated properly, especially in asthma, which is

TABLE 2 ] Mean (SD) Values ${ }^{a}$ of TLD, OD, Ex, and PI Observed Following Inhalation of Technetium-99m-labeled Monodisperse Salbutamol Aerosols of 1.5-, 3-, and 6- $\mu \mathrm{m}$ MMAD in 12 Patients With Mild to Moderate Asthma

\begin{tabular}{l|c|c|c|c}
\hline MMAD, $\mu \mathrm{m}$ & $\mathrm{TLD}^{\mathrm{b}}$ & $\mathrm{OD}^{\mathrm{b}}$ & $\mathrm{Ex}^{\mathrm{b}}$ & $\mathrm{PI}^{\mathrm{C}}$ \\
\hline 1.5 & $56.3(9.2)$ & $14.6(4.5)$ & $21.9(5.7)$ & 0.79 \\
3.0 & $51.0(8.9)$ & $30.6(7.2)$ & $8.3(1.5)$ & 0.60 \\
6.0 & $46.0(13.6)$ & $42.6(14.6)$ & $2.3(0.1)$ & 0.36 \\
\hline \hline
\end{tabular}

Ex = exhaled fraction data; $\mathrm{OD}=$ oropharyngeal deposition; $\mathrm{PI}=$ penetration index; TLD = total lung deposition. See Table 1 legend for expansion of other abbreviations.

${ }^{\mathrm{a}}$ Mean (SD) FEV 1 was 76.8 (11.4\%) predicted value.

balues of TLD, OD, and Ex are expressed as percentages of the delivered drug dose.

${ }^{\mathrm{C}} \mathrm{PI}$ is the ratio of drug deposition in the central and peripheral areas of the lung. (Modified with permission from Usmani et al. ${ }^{35,36}$ ) 
a disease of the whole airway tree. ${ }^{33}$ Lung deposition images show whole airway tree targeting can be achieved by small-particle polydisperse aerosols, but not with largeparticle polydisperse aerosols. ${ }^{36}$

Several studies have investigated the lung deposition of the small-particle aerosols of ICS monotherapy. The traditional chlorofluorocarbon (CFC)-propelled pMDI $\mathrm{BDP}$ suspension formulation delivers particles with a MMAD of 3 to $4 \mu \mathrm{m}$, leading to approximately $15 \%$ of the dose reaching the lung, whereas the remainder is deposited in the oropharynx..$^{31,32}$ In contrast, the newer solution-based HFA pMDI BDP formulation delivers particles with a MMAD of approximately $1 \mu \mathrm{m} .{ }^{27}$ Scintigraphic studies reveal that HFA BDP deposits more than $50 \%$ of the delivered drug dose in the airways, with effective penetration to the peripheral airways. ${ }^{31,32,41,42}$ Furthermore, although HFA BDP delivers particles with a MMAD of $1 \mu \mathrm{m}$, it includes a range of particles allowing some of the larger particles to deposit in both the intermediate and large airways. ${ }^{31,32,41}$ Similarly, in patients with mild asthma, small-particle HFA pMDI ciclesonide solution has been shown to achieve a uniform drug deposition in both central (44\%) and peripheral (56\%) airways. ${ }^{43}$ An in vitro study ${ }^{44}$ found that different HFA pMDIs of ICS may differ in the size of emitted particles: budesonide, $3.5 \mu \mathrm{m}$; fluticasone propionate, 2.8 $\mu \mathrm{m}$; BDP, $1.9 \mu \mathrm{m}$; and ciclesonide, $1.9 \mu \mathrm{m}$. Solution-based aerosols of BDP and ciclesonide had a greater proportion of fine particles (defined as particles $<3.1 \mu \mathrm{m}$ ) than did the HFA pMDI suspension aerosols of budesonide and fluticasone propionate. ${ }^{44}$

The Respimat (Boehringer Ingelheim) device is the only soft mist inhaler currently available on the market. This device does not require propellants because it is powered by the energy of a compressed spring inside the inhaler. Individual doses are delivered via a precisely engineered nozzle system as a slow-moving aerosol cloud (hence the term "soft mist"). ${ }^{22}$ In vitro ${ }^{45}$ and scintigraphic ${ }^{46}$ studies have shown that Respimat (Boehringer Ingelheim International $\mathrm{GmbH}$, Germany) emits a small-particle $(\sim 2 \mu \mathrm{m})$ aerosol with higher (51.6\%) levels of lung deposition, lower (19.3\%) oropharyngeal deposition, and greater peripheral lung penetration (peripheral-to-central ratio, 1.34) than do large-particle aerosols optimally administered from a DPI (lung deposition, 28.5\%; oropharyngeal deposition, $49.3 \%$; peripheral-to-central ratio, 0.95).

Deposition studies using a small-particle $(1.5 \mu \mathrm{m})$ HFA pMDI solution $\mathrm{BDP} /$ formoterol fixed-dose combination in patients with asthma have shown approximately onethird of drug is deposited in the peripheral lung region and two-thirds is deposited in the central lung region. ${ }^{47}$ A multidose DPI device delivering small particles $(1.5 \mu \mathrm{m})$ of $\mathrm{BDP} /$ formoterol also has shown a similar peripheral to central lung distribution. ${ }^{21}$ In contrast, several studies show that large-particle aerosols of fluticasone/salmeterol fixed-dose combination have poor peripheral airway penetration. ${ }^{48}$ Taken together, lung deposition studies conclusively demonstrate that smallparticle aerosols achieve not only better pulmonary deposition but also effective penetration into the peripheral areas of the lung.

\section{Oropharyngeal Deposition With Small-Particle Aerosols: Does It Matter Clinically?}

The oropharyngeal $90^{\circ}$ bend is the main determinant of loss of inhaled drug before it reaches the lungs. ${ }^{34}$ It is well documented ${ }^{31-33}$ that the majority of the inhaled drug dose delivered by conventional pMDIs deposits in the oropharynx, thus contributing to local side effects, such as candidiasis and dysphonia for ICSs. ${ }^{49}$ In addition, the drug deposited in the oropharynx can be swallowed into the gastrointestinal tract and may increase the risk of systemic adverse effects. ${ }^{50}$ In contrast, solution-based small-particle, HFA, pMDI aerosols deposit less drug in the oropharynx than do large-particle aerosols. ${ }^{41-43}$ Usmani et $\mathrm{al}^{35}$ found that $1.5-\mu \mathrm{m}$ salbutamol particles achieved lower (15\%) (Table 2) throat deposition than did 3- and $6-\mu \mathrm{m}$ particles (31\% and $43 \%$, respectively) (Table 2 ). The lower oropharyngeal deposition of an inhaled drug observed with a small-particle aerosol is likely to result from the lower plume velocity observed with these aerosols.

The reduction in oropharyngeal deposition with smallparticle ICS aerosols has clinical implications for local and systemic side effects. In patients with moderate to severe asthma, Bateman et $\mathrm{a}^{51}$ observed a significantly lower rate of oral adverse events (candidiasis and dysphonia) with small-particle ciclesonide aerosol than with large-particle fluticasone propionate aerosol. In patients with mild asthma, Newman et $\mathrm{al}^{43}$ observed a low (approximately 33\%) oropharyngeal deposition and high (approximately 52\%) lung deposition with smallparticle pMDI ciclesonide aerosol. Even when one-half of the drug dose targeted the distal lung region, this did not translate into greater pulmonary bioavailable adverse effects. ${ }^{41}$ In this regard, Derom et $\mathrm{al}^{52,53}$ found that small-particle ciclesonide aerosols (320 or $640 \mu \mathrm{g}$ 
daily) did not cause significant suppression of 24-hour urinary cortisol levels in contrast to findings with large-particle fluticasone propionate aerosols (500 or $1,000 \mu \mathrm{g}$ daily). Both ICS treatments decreased airway hyperresponsiveness to adenosine monophosphate, ${ }^{52}$ and methacholine. ${ }^{53}$ Thus, in this scenario, the therapeutic ratio (ie, the clinical benefit vs the adverse effects) actually may be improved with small-particle aerosols of ciclesonide.

With respect to ICS/LABA treatment, Huchon et $\mathrm{al}^{24}$ showed that morning urinary cortisol was significantly higher after inhalation of the small particles of an HFA pMDI BDP/formoterol fixed-dose combination $(400 \mu \mathrm{g} /$ $24 \mu \mathrm{g}$ daily, respectively) than after inhalation of the large particles of CFC pMDI BDP at the dose of $1,000 \mu \mathrm{g}$ daily together with CFC pMDI formoterol at $24 \mu$ g daily. Furthermore, treatment with small-particle aerosols achieved significantly better levels of asthma control, ${ }^{24}$ thus supporting the concept of an improved therapeutic ratio. In summary, compared with large-particle aerosols, small-particle aerosols result in lower oropharyngeal deposition, fewer local side effects, and less systemic absorption from the swallowed dose.

\section{Does Exhalation of Drug Matter With Small- Particle Aerosols?}

The inspiratory maneuver is a key determinant for the penetration and deposition of drug particles into the airways and, thus, the dose delivered to the target site. ${ }^{32}$ Particles that are not deposited may be exhaled. ${ }^{32}$ Previous in vitro modeling studies ${ }^{27,54,55}$ showed a large (approximately $80 \%$ ) proportion of inhaled small particles could be exhaled because they were able to remain airborne for a considerable time, even with a breath-hold pause maximizing the effect of gravitational sedimentation. ${ }^{35}$ Particles that remain airborne in the larger airways are likely to be exhaled because of a greater settling distance before coming into contact with the airway walls. However, these in vitro modeling studies $^{27,54,55}$ did not account for features of inhaled drug delivery in vivo that can affect aerosol deposition in the lungs, such as the breath-hold pause that retains most particles within the airways or the effect of different inhalation maneuvers when using pMDIs or DPIs. In their in vivo study, Usmani et $\mathrm{al}^{36}$ found that, although the exhaled fraction of a monodisperse salbutamol aerosol increased with the decreasing particle size (Table 2), the small particles were exhaled far less than previously predicted by in vitro models. Studies performed in both healthy subjects ${ }^{31,33,56}$ and patients with asthma, ${ }^{21,43,44}$ using commercial polydisperse aerosols, showed that the exhaled fraction of smallparticle ICS aerosols was similar to that observed with large-particle aerosols, ranging between $2 \%$ and $14 \%$ (Table 3). In conclusion, small-particle aerosols are not exhaled to any significantly greater level than are large-particle aerosols when assessed using in vivo lung deposition studies.

\section{Are Small-Particle Aerosols More Effective Than Large-Particle Aerosols?}

Several studies have shown that small-particle aerosols improve markers of small-airway dysfunction and inflammation in both asthma and COPD. ${ }^{13-15,57,58}$ However, the question remains ${ }^{59}$ as to whether treatment with small-particle aerosols leads to added benefit in patients with asthma or COPD when compared directly with large-particle aerosols. Few studies have compared the effect of the same drug delivered as a small- or a large-particle aerosol. Such head-to-head comparisons are limited to CFC-driven vs HFA-driven BDP, but with the CFC propellants no longer available, additional comparisons cannot be made. Findings from studies comparing different drugs delivered by different inhaler devices are difficult to interpret. In addition, the lack of direct comparison of small- vs large-particle aerosol therapies using the same ICS also may influence the validity of equivalent dosages reported by current guidelines. ${ }^{60}$

TABLE 3 ] Percentage of Ex Observed With ICSs of Different Sizes

\begin{tabular}{|c|c|c|c|}
\hline ICS & $M M A D, \mu \mathrm{m}$ & Ex & Reference \\
\hline Ciclesonide HFA pMDI & 1.1 & 3.70 & Newman et $\mathrm{al}^{43}$ \\
\hline BDP HFA pMDI & 1.1 & $6.0,14.0$ & Leach et $\mathrm{al}^{31,33}$ \\
\hline BDP/formoterol DPI & 1.5 & 3.30 & Corradi et $\mathrm{al}^{21}$ \\
\hline BDP CFC pMDI & 3.5 & 3.0 & Leach et $\mathrm{al}^{31,33}$ \\
\hline Fluticasone CFC pMDI & 2.4 & 2.0 & de Vries et al $^{44}$ \\
\hline Budesonide DPI & 3.7 & 1.0 & Warren et $\mathrm{al}^{56}$ \\
\hline
\end{tabular}

$\mathrm{CFC}=$ chlorofluorocarbon. See Table 1 and 2 legends for expansion of other abbreviations. 
A recent review of the literature ${ }^{14}$ revealed that, in controlled clinical trials involving highly selected adult patients with asthma who fulfilled precise inclusion and exclusion criteria, treatments with small-particle aerosols achieved efficacy similar to that of large-particle aerosols. However, patients enrolled in controlled clinical trials may not represent the heterogeneity of patients with asthma seen in real-life daily clinical practice. ${ }^{61}$ As little as $6 \%$ of real-life patients with asthma fit the criteria of controlled clinical trials, which calls into question the application of clinical trial results to patients seen in daily clinical practice. ${ }^{62}$ The same review found that, in real-life asthma studies, treatment with small-particle aerosols resulted in greater daily asthma control; better quality-of-life indexes; and, importantly, lower daily ICS dose, when compared with large-particle aerosol treatment. ${ }^{14}$ Recently, the effectiveness of small-particle ICS pMDI therapy was compared with that of large-particle ICS treatment in children with asthma who were either initiating or stepping up ICS therapy. ${ }^{63}$ Over 1 year, small-particle ICS was more effective than large-particle ICS for asthma control and as effective as adding a LABA in a fixed-dose combination inhaler. ${ }^{63}$ Noticeably, the differential effects of small- vs large-particle ICS were more pronounced in younger than in older children. ${ }^{63}$ The key studies comparing the effects of small-particle aerosols vs large-particle aerosols in adult patients with asthma or COPD are reported in e-Tables 1-3.

In summary, randomized controlled trials show smallparticle aerosols are as effective as large-particle aerosols. However, real-life studies reveal small-particle aerosols are more efficacious in patients' reported outcomes than are large-particle aerosols at much lower daily ICS doses.

\section{Do Small-Particle Aerosols Cause More Adverse Effects Than Do Large-Particle Aerosols?}

Data obtained from large-scale asthma studies showed that the overall incidence of at least one adverse event was significantly lower in patients treated with smallparticle HFA, pMDI, BDP aerosols (46\%) than in patients receiving the same drug as large-particle aerosols (59\%) and was equal to that of HFA placebo (51\%). ${ }^{64,65}$ Most adverse events were reported as mild to moderate. Administration of high doses (up to 1,000 $\mu \mathrm{g} /$ $60 \mu \mathrm{g}$ ) of small-particle BDP/formoterol aerosol combination delivered by means of HFA pMDI was well tolerated, with a safety profile generally similar to that of formoterol alone. ${ }^{66}$
Increased distal lung deposition of ICS might be expected to be associated with increased systemic effects, particularly the suppression of cortisol production. However, reassuringly, data from clinical trials have not documented any increased risk of systemic effects with an inhaled small-particle ICS formulation ${ }^{64,65,67-69}$ or a small-particle ICS/LABA combination formulation. ${ }^{66,70,71}$ Treatment with small-particle HFA pMDI, ICS/LABA, solution-based aerosols has resulted in less suppression of the hypothalamic-pituitaryadrenal axis, as assessed by means of cortisol levels, than has treatment with an equipotent dose of large-particle CFC, pMDI ICS plus LABA. ${ }^{72}$ However, because ICSs may differ substantially in their gastrointestinal bioavailability, findings from one drug should be generalized with caution to other drugs. The available data suggest that the more distal deposition of smallparticle formulations of ICS are safe in patients with asthma, and, for some drugs, may even result in a reduced effect on the hypothalamic-pituitary-adrenal axis, probably through less oropharyngeal deposition and, hence, decreased gastrointestinal bioavailability.

\section{Do You Need to Add a Spacer to Small-Particle Aerosol Devices or Use a Different Inhaler Technique Than With Large-Particle Aerosol Devices?}

A spacer is an extension device placed at the interface between the patient and the pMDI. ${ }^{73,74}$ Valved holding chambers (VHCs) have a one-way valve at the mouthpiece to prevent exhalation into the chamber and to allow the patient to breathe from a "standing aerosol cloud," thus reducing the need of breath-hand coordination. ${ }^{73,74}$ Both spacers and VHCs are used with pMDIs to increase the efficiency of aerosol delivery. ${ }^{73,74}$ They reduce the aerosol speed and allow for the evaporation of propellant from larger droplets thereby reducing oropharyngeal deposition and increasing deep lung deposition. ${ }^{73,74}$ Some VHCs, such as the AeroChamber Plus Flow-Vu (Monaghan Medical Corporation), can indicate whether the patient is inhaling correctly by means of a whistle when the patient is inhaling too quickly. ${ }^{74}$

In theory, the use of small-particle aerosol therapy should reduce the need for a spacer device or a VHC because they have (1) a lower impact force on the back of the patient's throat, (2) a slower plume, (3) a longer time for particle evaporation, and (4) reduced throat deposition. ${ }^{19}$ Because of their less forceful spray and softer plume, small-particle aerosols may deposit a smaller amount of drug into the spacer walls, with a 
TABLE 4 ] Key Aspects and Contrasting Points Related to Small-Particle Aerosols

\begin{tabular}{|c|c|}
\hline Question & Key Point, Contrast, or Observation \\
\hline Is particle size important to achieve better lung deposition? & $\begin{array}{l}\text { - Particle size markedly influences the deposition of an } \\
\text { inhaled drug and its relative distribution within the large } \\
\text { and small airways. } \\
\text { - Small-particle aerosols improve drug deposition and } \\
\text { regional airway distribution within the lungs. }\end{array}$ \\
\hline $\begin{array}{l}\text { Oropharyngeal deposition with small-particle aerosols: does } \\
\text { it matter clinically? }\end{array}$ & $\begin{array}{l}\text { - Drug deposition at the oropharyngeal level is lower with } \\
\text { small-particle aerosols than with large-particle aerosols. }\end{array}$ \\
\hline Does exhalation of drug matter with small-particle aerosols? & $\begin{array}{l}\text { - In in vivo lung deposition studies, small-particle aerosols } \\
\text { are not exhaled to any greater significant level than are } \\
\text { large-particle aerosols. } \\
\text { - In vitro studies previously suggested exhalation of small } \\
\text { particles did not model therapeutic aerosol inhalation with } \\
\text { a breath-hold pause. }\end{array}$ \\
\hline $\begin{array}{l}\text { Are small-particle aerosols more effective than large- } \\
\text { particle aerosols? }\end{array}$ & $\begin{array}{l}\text { - In randomized controlled clinical trials, small-particle } \\
\text { aerosols are as effective as large-particle aerosols. } \\
\text { - In real-life studies, small-particle aerosols are more } \\
\text { efficacious in patients' reported outcomes than are large- } \\
\text { particle aerosols. } \\
\text { - Studies comparing the same drug inhaled as small-or } \\
\text { large-particle aerosol are limited essentially to BDP } \\
\text { delivered as a CFC or HFA formulation. }\end{array}$ \\
\hline $\begin{array}{l}\text { Do small-particle aerosols cause more adverse effects than } \\
\text { do large-particle aerosols? }\end{array}$ & $\begin{array}{l}\text { - The use of small-particle aerosols is safe in patients with } \\
\text { asthma and might result in a reduced effect on the } \\
\text { hypothalamic-pituitary-adrenal axis, probably through } \\
\text { less oropharyngeal deposition and hence decreased } \\
\text { gastrointestinal bioavailability. } \\
\text { - Local oropharyngeal adverse effects are fewer with small- } \\
\text { particle aerosols. } \\
\text { - Comparisons of the systemic effects of ICSs have been } \\
\text { performed mainly with ICSs that have a high gastroin- } \\
\text { testinal bioavailability. More studies are needed with ICSs } \\
\text { with low gastrointestinal bioavailability. }\end{array}$ \\
\hline $\begin{array}{l}\text { Do you need to add a spacer to small-particle aerosol } \\
\text { devices or use a different inhaler technique than with } \\
\text { large-particle aerosol devices? }\end{array}$ & $\begin{array}{l}\text { - The use of spacers or holding chambers with pMDIs } \\
\text { delivering small-particles aerosols reduces throat } \\
\text { deposition and improves drug delivery to the lungs. } \\
\text { - This can be a valuable option for patients with difficulties } \\
\text { achieving an adequate inhalation technique. } \\
\text { - Studies are needed to assess whether the beneficial } \\
\text { effects are due to a better inhalation technique when a } \\
\text { spacer is used. }\end{array}$ \\
\hline
\end{tabular}

See Table 1 and 3 legends for expansion of abbreviations.

consequent increase in lung deposition. Roller et $\mathrm{al}^{75}$ found that inhalation of small-particle BDP aerosol delivered via an HFA pMDI with the AeroChamber Plus VHC resulted in high lung deposition and marked decrease in oropharyngeal deposition, compared with the same formulation inhaled via the pMDI alone. Recently, a small-particle flunisolide aerosol delivered by an HFA pMDI with a built-in spacer has been introduced in the market for asthma treatment. This formulation enhances the pulmonary/ oropharyngeal deposition ratio further compared with that of the traditional formulation without a spacer. $^{76}$
The increased drug deposition in the lungs with spacers or VHCs added to pMDIs delivering small-particle aerosols may raise concerns about the possibility of increased systemic exposure to drugs, especially ICS (see also question 5). However, studies performed in both healthy subjects and patients with asthma show that this does not seem to be the case. Singh et $\mathrm{al}^{77}$ found in healthy volunteers that adding the AeroChamber Plus VHC to an HFA pMDI delivering small-particle BDP/ formoterol aerosol did not affect the systemic exposure of these drugs compared with pMDI alone. Similar results were obtained in adolescents with asthma. ${ }^{78}$ The results of these studies are particularly relevant because 
they suggest that the use of pMDIs delivering smallparticle aerosols in conjunction with the AeroChamber Plus VHC does not affect the safety profile of the product. More studies with other drugs are needed.

In summary, addition of spacers or VHCs to pMDIs delivering small-particle aerosols further reduces throat deposition and improves drug delivery to the lungs. Adding VHCs to small-particle-based pMDIs can be a valuable option for certain patient groups, such as those with difficulties in achieving an adequate inhalation technique.

\section{Summary and Conclusion}

A summary of key points and contrasts related to the various questions is reported in Table 4 . Pathophysiologic evidence for small-airway dysfunction and the clinical emergence of a small-airway phenotype suggest that we should consider treating the smallairway region when reviewing patients with asthma or COPD clinically. In view of the increasing recognition of the role of small airways in asthma and COPD, it is not unexpected that small-particle aerosols are beginning to show a greater impact than traditional large-particle aerosols on asthma and COPD outcomes. A recent review ${ }^{14}$ of the available literature suggests that, in randomized controlled trials, small-particle aerosol therapy is as good as large-particle aerosol therapy. However, none of these randomized trials selected patients with documented baseline distal airway dysfunction, in whom the effects of a targeted smallparticle aerosol treatment potentially could be larger. The findings of recent studies ${ }^{13-15}$ focusing on small airways should be confirmed in large trials in patients with different patterns of severity and control. More importantly, through real-life studies, it is becoming evident that small-particle aerosol therapy has advantages over large-particle therapy that are relevant to our daily practice, as opposed to findings in selective populations entered into randomized clinical trials. ${ }^{61,62}$

Definitive answers to the questions posed in this article are yet to be established fully and will require collaboration and participation among academics and the pharmaceutical industry specifically to undertake head-to-head trials of small- vs large-particle aerosol therapy truly to inform us whether small-particle therapy will be useful to practicing clinicians. In addition, performing trials exploring potential phenotypic differences in response to small- or large-particle aerosols would be important. There have been multiple strong calls to action to undertake definitive clinical trials in this area, ${ }^{15,79-81}$ and now is the time to conduct these definitive studies. The respiratory care community needs to make a concerted effort to convince funding agencies to provide support for these much needed studies and to convince the pharmaceutical industry to supply the same corticosteroids in large- and small-particle formulations to make these studies feasible.

\section{Acknowledgments}

Financial/nonfinancial disclosures: The authors have reported to CHEST the following: F. L. reports personal fees and honoraria for speaking and advisory boards from AstraZeneca, Boehringer Ingelheim, Chiesi, Cipla, Teva, and Zentiva outside the submitted work. S. P. reports fees for consultancies or speaking from AstraZeneca, Boehringer Ingelheim, GlaxoSmithKline, and Sandoz outside the submitted work. O. S. U. reports grants from AstraZeneca, Chiesi, GlaxoSmithKline, Prosonix, Sandoz, Takeda, and Zentiva and personal fees from Aerocrine, Boehringer Ingelheim, Chiesi, Napp, Mundipharma, and Sandoz outside the submitted work.

All authors are member of the Aerosol Drug Management Improvement Team (ADMIT), a nonprofit European consortium of physicians with clinical and research expertise on the topic of inhaled therapy for respiratory diseases.

Role of sponsors: The sponsor had no role in the design of the study, the collection and analysis of the data, or the preparation of the manuscript.

Other contributions: Members and affiliations of the Aerosol Drug Management Improvement Team (ADMIT): P. J. Barnes, National Heart and Lung Institute, Imperial College London, England; L.

Corbetta, Department of Experimental and Clinical Medicine, Careggi University Hospital, Florence, Italy; C. J. Corrigan, Department of Respiratory Medicine and Allergy, King's College London School of Medicine, London, England; B. L. Chawes, Copenhagen Prospective Studies on Asthma in Childhood, Herlev and Gentofte Hospital, University of Copenhagen, Copenhagen, Denmark; P. N. R.

Dekhuijzen, Radboud University Nijmegen Medical Centre, The Netherlands; T. Hausen, General Practitioner, Essen, Germany; F. Lavorini, Department of Experimental and Clinical Medicine, Careggi University Hospital, Florence, Italy; M. L. Levy, General Practitioner and Respiratory Lead, Harrow, London, England; S. Pedersen, Pediatric Research Unit, University of Southern Denmark, Kolding Hospital, Kolding, Denmark; N. Roche, Respiratory Medicine Department Hôpital Cochin (AP-HP), Paris, France; J. Sanchis, Respiratory Medicine Department, Hospital Santa Creu i Sant Pau, Barcelona University, Spain; O. S. Usmani, National Heart and Lung Institute, Imperial College London and Royal Brompton Hospital, London, England; and W. Vincken, Respiratory Division, Ziekenhuis University Brussel, Brussels, Belgium.

Additional information: The e-Tables can be found in the Supplemental Materials section of the online article.

\section{References}

1. Darquenne C, Fleming JS, Katz I, et al. Bridging the gap between science and clinical efficacy: physiology, imaging and modelling of aerosol in the lung. J Aerosol Med Pulm Drug Deliv. 2016;29(2): $1-19$.

2. Weibel ER. Morphometry of the Human Lung. Berlin, Germany: Springer-Verlag; 1963,p4-9.

3. Hogg JC, Chu F, Utokaparch S, et al. The nature of small-airway obstruction in chronic obstructive pulmonary disease. $N$ Engl J Med. 2004;350(26):2645-2653. 
4. Hamid Q, Song Y, Kotsimbos TC, et al. Inflammation of small airways in asthma. J Allergy Clin Immunol. 1997;100(1):44-51.

5. Yanai M, Sekizawa K, Ohrui T, Sasaki H, Takishima T. Site of airway obstruction in pulmonary disease: direct measurement of intrabronchial pressure. J Appl Physiol. 1992;72(3):1016-1023.

6. in't Veen JC, Beekman AJ, Bel EH, Sterk PJ. Recurrent exacerbations in severe asthma are associated with enhanced airway closure during stable episodes. Am J Respir Crit Care Med. 2000;161(6):1902-1906.

7. Scichilone N, Battaglia S, Taormina S, Modica V, Pozzecco E, Bellia V. Alveolar nitric oxide and asthma control in mild untreated asthma. J Allergy Clin Immunol. 2013;131(6):1513-1517.

8. Wenzel SE. Asthma: defining of the persistent adult phenotypes. Lancet. 2006;368(9537):804-813.

9. Kraft M, Djukanovic R, Wilson S, Holgate ST, Martin RJ. Alveolar tissue inflammation in asthma. Am J Respir Crit Care Med. 1996;154(5):1505-1510.

10. Kraft M, Pak J, Martin RJ, Kaminsky D, Irvin CG. Distal lung dysfunction at night in nocturnal asthma. Am J Respir Crit Care Med. 2001;163(7):1551-1556.

11. Kaminsky DA, Irvin CG, Gurka DA, et al. Peripheral airways responsiveness to cool, dry air in normal and asthmatic individuals. Am J Respir Crit Care Med. 1995;152(6 pt 1):1784-1790.

12. D’Amato G, Liccardi G, D'Amato M, Cazzola M. Outdoor air pollution climatic changes and allergic bronchial asthma. Eur Respir J. 2002;20(3):763-776.

13. Usmani OS. Small airways dysfunction in asthma: evaluation and management to improve asthma control. Allergy Asthma Immunol Res. 2014;6(5):376-388.

14. Usmani OS. Small-airway disease in asthma: pharmacological considerations. Curr Opin Pulm Med. 2015;21(1):55-67.

15. Usmani OS. Treating the small airways. Respiration. 2012;84(6): 441-453.

16. Chapman KR, Fogarty CM, Peckitt C, et al. Delivery characteristics and patients' handling of two single-dose dry-powder inhalers used in COPD. Int J Obstruct Pulmon Dis. 2011;6:353-363.

17. Colthorpe P, Voshaar T, Kieckbusch T, Cuoghi E, Jauernig J. Delivery characteristics of a low-resistance dry-powder inhaler used to deliver the long-acting muscarinic antagonist glycopyrronium. J Drug Assess. 2013;2(1):11-16.

18. Lock DJ, Watkins A, Munro A. DPI performance modelling using an inhalation simulator and oropharyngeal model: a more patientrelevant approach for device development. Paper presented at: Drug Delivery to the Lungs DDL25 Conference; December 10, 2014; Edinburgh, UK.

19. Lavorini F, Fontana GA, Usmani OS. New inhaler devices; the good, the bad and the ugly. Respiration. 2014;88(1):3-15.

20. Labiris NR, Dolovich MB. Pulmonary drug delivery. Part I: physiological factors affecting therapeutic effectiveness of aerosolized medications. Br J Clin Pharmacol. 2003;56(6):588-599.

21. Corradi M, Chrystyn H, Cosio BG, et al. NEXThaler, an innovative dry powder inhaler delivering an extrafine fixed combination of beclometasone and formoterol to treat large and small airways in asthma. Exp Opin Drug Deliv. 2014;11(9):1497-1506.

22. Dalby RN, Eicher J, Zierenberg B. Development of Respimat Soft Mist inhaler and its clinical utility in respiratory disorders. Med Devices (Auckl). 2011;4:145-155.

23. Hoshino M. Comparison of effectiveness in ciclesonide and fluticasone propionate on small airway function in mild asthma. Allergol Int. 2010;59(1):59-66.

24. Huchon G, Magnussen $\mathrm{H}$, Chuchalin A, et al. Lung function and asthma control with beclomethasone and formoterol in a single inhaler. Respir Med. 2009;103(1):41-49.

25. Papi A, Paggiaro P, Nicolini G, et al; and the ICAT SE study group. Beclomethasone/formoterol vs fluticasone/salmeterol inhaled combination in moderate to severe asthma. Allergy. 2007;62(10): 1182-1188.
26. Postma DS, Roche N, Colice G, et al. Comparing the effectiveness of small-particle versus large-particle inhaled corticosteroid in COPD. Int J Chron Obstruct Pulmon Dis. 2014;9:1163-1186.

27. de Boer AH, Gjaltema D, Hagedoorn P, Frijlink HW. Can 'extrafine' dry powder aerosols improve lung deposition? Eur J Pharm Biopharm. 2015;96:143-151.

28. Chrystyn H, Price D. Not all asthma inhalers are the same: factors to consider when prescribing an inhaler. Prim Care Respir J. 2009;18(4) 243-249.

29. Mitchell J, Newman S, Chan HK. In vitro and in vivo aspects of cascade impactor tests and inhaler performance: a review. AAPS PharmSciTech. 2007;8(4):E110.

30. Laube B, Janssens HM, de Jongh FH, et al. What the pulmonary specialist should know about the new inhalation therapies. Eur Respir J. 2011;37(6):1308-1331.

31. Leach CL, Davidson PJ, Hasselquist BE, Boudreau RJ. Lung deposition of hydrofluoroalkane-134a beclomethasone is greater than that of chlorofluorocarbon fluticasone and chlorofluorocarbon beclomethasone: a cross-over study in healthy volunteers. Chest. 2002;122(2):510-516

32. Agertoft L, Laulund LW, Harrison LI, Pedersen S. Influence of particle size on lung deposition and pharmacokinetics of beclomethasone dipropionate in children. Pediatr Pulmonol. 2003;35(3):192-199.

33. Leach CL, Davidson PJ, Boudreau RJ. Improved airway targeting with the CFC-free HFA beclomethasone metered-dose inhaler compared with CFC-beclomethasone. Eur Respir J. 1998;12(6): 1346-1353.

34. Zanen P, Laube BL. Targeting the lungs with therapeutic aerosols. In Bisgaard H, O'Callaghan C, Smaldone G, eds. Drug Delivery to the Lungs. New York, NY: Marcel Dekker; 2001:211-261.

35. Usmani OS, Biddiscombe MF, Nightingale JA, Underwood SR, Barnes PJ. Effects of bronchodilator particle size in asthmatic patients using monodisperse aerosols. J Appl Physiol (1985). 2003;95(5):2106-2112.

36. Usmani OS, Biddiscombe MF, Barnes PJ. Regional lung deposition and bronchodilator response as a function of beta2-agonist particle size. Am J Respir Crit Care Med. 2005;172(12):1497-1504.

37. Zanen P, Go LT, Lammers JW. Optimal particle size for beta 2 agonist and anticholinergic aerosols in patients with severe airflow obstruction. Thorax. 1996;51(10):977-980.

38. Borrill ZL, Houghton CM, Tal-Singer R, et al. The use of plethysmography and oscillometry to compare long-acting bronchodilators in patients with COPD. Br J Clin Pharmacol. 2008;65(2):244-252.

39. Al-Bazzaz FJ. Single-breath nitrogen washout: effects of alterations of lung volumes and elastic recoil. Chest. 1979;76(1):83-88.

40. Bourdin A, Paganin F, Préfaut C, Kieseler D, Godard P, Chanez P. Nitrogen washout slope in poorly controlled asthma. Allergy. 2006;61(1):85-89.

41. Leach CL. Effect of formulation parameters on hydrofluoroalkanebeclomethasone dipropionate drug deposition in humans. J Allergy Clin Immunol. 1999;104(6):S250-S252.

42. Leach CL, Bethke TD, Boudreau RJ, et al. Two-dimensional and three-dimensional imaging show ciclesonide has high lung deposition and peripheral distribution: a nonrandomized study in healthy volunteers. J Aerosol Med. 2006;19(2):117-126.

43. Newman S, Salmon A, Nave R, Drollmann A. High lung deposition of $99 \mathrm{mTc}$-labeled ciclesonide administered via HFA-MDI to patients with asthma. Respir Med. 2006;100(3):375-384.

44. de Vries TW, Rottier BL, Gjaltema D, Hagedoorn P, Frijlink HW, de Boer AH. Comparative in vitro evaluation of four corticosteroid metered dose inhalers: consistency of delivered dose and particle size distribution. Respir Med. 2009;103(8):1167-1173.

45. Zierenberg B. Optimizing the in vitro performance of Respimat. J Aerosol Med. 1999;12(suppl 1):S19-S24.

46. Pitcairn G, Reader S, Pavia D, Newman S. Deposition of corticosteroid aerosol in the human lung by Respimat Soft Mist 
inhaler compared to deposition by metered dose inhaler or by Turbuhaler dry powder inhaler. J Aerosol Med. 2005;18(3):264-272.

47. Nicolini G, Scichilone N, Bizzi A, et al. Beclomethasone/formotero fixed combination for the management of asthma: patient considerations. Ther Clin Risk Manag. 2008;4(5):855-864.

48. Leach CL, Kuehl PJ, Chand R, Ketai L, Norenberg JP, McDonald JD Characterization of respiratory deposition of fluticasone-salmeterol hydrofluoroalkane-134a and hydrofluoroalkane-134a beclomethasone in asthmatic patients. Ann Allergy Asthma Immunol. 2012;108(3):195-200.

49. Chrystyn H. Methods to identify drug deposition in the lungs following inhalation. Br J Clin Pharmacol. 2001;51(4):289-299.

50. Lipworth BJ. Pharmacokinetics of inhaled drugs. Br J Clin Pharmacol. 1996;42(6):697-705.

51. Bateman ED, Linnhof AE, Homik L, et al. Comparison of twice-daily inhaled ciclesonide and fluticasone propionate in patients with moderate-to-severe persistent asthma. Pulm Pharmacol Ther. 2008;21(2):264-275.

52. Derom E, Van De Velde V, Marissens S, et al. Effects of inhaled ciclesonide and fluticasone propionate on cortisol secretion and airway responsiveness to adenosine 5 'monophosphate in asthmatic patients. Pulm Pharmacol Ther. 2005;18(5):328-336.

53. Derom E, Louis R, Tiesler C, Engelstätter R, Kaufman JM, Joos GF Effects of ciclesonide and fluticasone on cortisol secretion in patients with persistent asthma. Eur Respir J. 2009;33(6):1277-1286.

54. Gerrity TR, Lee PS, Hass FJ, Marinelli A, Werner P, Lourenço RV. Calculated deposition of inhaled particles in the airway generations of normal subjects. J Appl Physiol. 1979;47(4):867-873.

55. Heyder J. Assessment of airway geometry with inert aerosols. J Aerosol Sci. 1989;2:89-97.

56. Warren S, Taylor G, Smith J, Buck H, Parry-Billings M. Gamma scintigraphic evaluation of a novel budesonide dry powder inhaler using a validated radiolabeling technique. J Aerosol Med. 2002;15(1) $15-25$

57. Usmani OS, Barnes PJ. Assessing and treating small airways disease in asthma and chronic obstructive pulmonary disease. Ann Med. 2012;44(2):146-156

58. Scichilone N, Contoli M, Paleari D, et al. Assessing and accessing the small airways: implications for asthma management. Pulm Pharmacol Ther. 2013;26(2):172-179.

59. Kelly HW. Ultrafine-particle inhalers, the Holy Grail of inhaled corticosteroid therapy, or not! J Allergy Clin Immunol Pract. 2015;3(5):732-733.

60. National Asthma Education and Prevention Program. Expert Panel Report 3: Guidelines for the Diagnosis and Management of AsthmaFull Report No.: 07-4051. Bethesda, MD: National Heart, Lung, and Blood Institute; 2007.

61. Roche N, Reddel HK, Agusti A, Bateman ED, et al; and the Respiratory Effectiveness Group. Integrating real-life studies in the global therapeutic research framework. Lancet Respir Med. 2013;1(10):e29-e30

62. Herland K, Akselsen JP, Skjønsberg OH, Bjermer L. How representative are clinical study patients with asthma or COPD for a larger 'real life' population of patients with obstructive lung disease? Respir Med. 2005;99(1):11-19.

63. van Aalderen WM, Grigg J, Guilbert TW, et al. Small-particle inhaled corticosteroid as first-line or step-up controller therapy in childhood asthma. J Allergy Clin Immunol Pract. 2015;3(5). 721.e16731.e16.

64. VandenBurgt JA, Busse WW, Martin RJ, Szefler SJ, Donnell D. Efficacy and safety overview of a new inhaled corticosteroid, QVAR (hydrofluoroalkane-beclomethasone extrafine inhalation aerosol), in asthma. J Allergy Clin Immunol. 2000;106(6):1209-1226.
65. Thompson PJ, Davies RJ, Young WF, et al. Safety of hydrofluoalkane-134a beclomethasone dipropionate extrafine aerosol. Respir Med. 1998;92(suppl A):33-39.

66. Singh D, Piccinno A, Borrill Z, et al. Tolerability of high cumulative doses of the HFA modulite beclomethasone dipropionate/formoterol combination inhaler in asthmatic patients. Pulm Pharmacol Ther. 2008;21(3):551-557.

67. Busse WW, Brazinsky S, Jacobson K, et al. Efficacy response of inhaled beclomethasone dipropionate in asthma is proportional to dose and is improved by formulation with a new propellant. J Allergy Clin Immunol. 1999;104(6):1215-1222.

68. Davies RJ, Stampone P, O’Connor BJ. Hydrofluroalkane-134a beclomethasone dipropionate extrafine aerosol provides equivalent asthma control to chlorofluorocarbon beclomethasone dipropionate at approximately half the total daily dose. Respir Med. 1998;92(suppl A):23-31.

69. van Schayck CP, Donnell D. The efficacy and safety of QVAR (hydrofluoroalkane-beclomethasone dipropionate extrafine aerosol) in asthma (part I): an update of clinical experience in adults. Int J Clin Pract. 2004;58(7):678-688.

70. Papi A, Paggiaro PL, Nicolini G, et al. Beclomethasone/formoterol vs. budesonide/formoterol combination therapy in asthma. Eur Respir J. 2007;29:682-689.

71. Bousquet J, Poli G, Acerbi D, Monno R, Ramael S, Nollevaux F. Systemic exposure and implications for lung deposition with an extra-fine hydrofluoroalkane beclomethasone dipropionate/ formoterol fixed combination. Clin Pharmacokinet. 2009;48(6): 347-358.

72. Ohbayashi H, Adachi M. Hydrofluoroalkane-beclomethasone dipropionate effectively improves airway eosinophilic inflammation including the distal airways of patients with mild to moderate persistent asthma as compared with fluticasone propionate in a randomized open double-cross study. Allergol Int. 2008;57(3):1-9.

73. Lavorini F, Fontana GA. Targeting drugs to the airways: the role of spacer devices. Expert Opin Drug Deliv. 2009;6(1):91-102.

74. Nikander K, Nicholls C, Denyer J, Pritchard J. The evolution of spacers and valved holding chambers. J Aerosol Med Pulm Drug Deliv. 2014;27(suppl 1):S-4-S-23.

75. Roller CM, Zhang G, Troedson RG, Leach CL, Le Souëf PN, Devadason SG. Spacer inhalation technique and deposition of extrafine aerosol in asthmatic children. Eur Respir J. 2007;29(2): 299-306.

76. Berger WE, Tashkin DP. Flunisolide hydrofluoroalkane with integrated spacer for treating asthma: an updated review. Allergy Asthma Proc. 2015;36(2):105-115.

77. Singh D, Collarini S, Poli G, Acerbi D, Amadasi A, Rusca A. Effect of AeroChamber Plus ${ }^{\mathrm{TM}}$ on the lung and systemic bioavailability of beclomethasone dipropionate/formoterol pMDI. Br J Clin Pharmacol. 2011;72(6):932-939.

78. Kuna P, Govoni M, Lucci G, Scuri M, Acerbi D, Stelmach I. Pharmacokinetics and pharmacodynamics of an extrafine fixed pMDI combination of beclomethasone dipropionate/formoterol fumarate in adolescent asthma. Br J Clin Pharmacol. 2015;80(3) 569-580.

79. Perez T. Is it really time to look at distal airways to improve asthma phenotyping and treatment. Eur Respir J. 2011;38(3):1252-1254.

80. Lipworth B. Targeting the small airways asthma phenotype: if we can reach it, should we treat it? Ann Allergy Asthma Immunol. 2013;110(4):233-239.

81. Kelly HW. Alveolar nitric oxide concentration, small airways inflammation, and targeted asthma therapy: are we there yet? J Allergy Clin Immunol. 2010;126(4):736-737. 